\title{
Correction to: A Lanosteryl triterpene from Protorhus longifolia augments insulin signaling in type 1 diabetic rats
}

Sihle Ephraim Mabhida ${ }^{1 *}$, Rabia Johnson ${ }^{2,3}$, Musawenkosi Ndlovu', Nonhlakanipho Felicia Sangweni", Johan Louw², Andrew Opoku ${ }^{1}$ and Rebamang Anthony Mosa ${ }^{1}$

\section{Correction to: BMC complementary and alternative medicine (2018) 18:265 DOI: https://doi.org/ \\ 10.1186/s12906-018-2337-z}

Following publication of the original article [1], the author reported that the first names and last names of all authors were reversed. The original article has been corrected.

Incorrect names in the original article:

1. Mabhida Sihle Ephraim

2. Johnson Rabia

3. Ndlovu Musawenkosi

4. Sangweni Nonhlakanipho Felicia

5. Louw Johan

6. Opoku Andrew

7. Mosa Rebamang Anthony

\section{Correct names:}

1. Sihle Ephraim Mabhida

2. Rabia Johnson

3. Musawenkosi Ndlovu

4. Nonhlakanipho Felicia Sangweni

5. Johan Louw

6. Andrew Opoku

7. Rebamang Anthony Mosa

\section{Author details}

'Department of Biochemistry and Microbiology, University of Zululand, Private Bag X1001, KwaDlangezwa 3886, South Africa. ${ }^{2}$ Biomedical Research and Innovation Platform (BRIP), South African Medical Research Council, Tygerberg 7505, South Africa. ${ }^{3}$ Division of Medical Physiology, Faculty of Medicine and Health Sciences, Stellenbosch University, Tygerberg 7505, South Africa.
Published online: 04 December 2018

\section{Reference}

1. Ephraim, et al. A Lanosteryl triterpene from Protorhus longifolia augments insulin signaling in type 1 diabetic rats. BMC Complement Altern Med. 2018 18(265) https://doi.org/10.1186/s12906-018-2337-z.

\footnotetext{
*Correspondence: sihlemabhida@gmail.com

1 Department of Biochemistry and Microbiology, University of Zululand,

Private Bag X1001, KwaDlangezwa 3886, South Africa
}

(c) The Author(s). 2018 Open Access This article is distributed under the terms of the Creative Commons Attribution 4.0 International License (http://creativecommons.org/licenses/by/4.0/), which permits unrestricted use, distribution, and reproduction in any medium, provided you give appropriate credit to the original author(s) and the source, provide a link to the Creative Commons license, and indicate if changes were made. The Creative Commons Public Domain Dedication waiver (http://creativecommons.org/publicdomain/zero/1.0/) applies to the data made available in this article, unless otherwise stated. 